\title{
Developing a New Generation of Leadership at the University of Calgary Case Study on the Maier Student Leadership Program
}

\section{Dr. Lynne Cowe Falls, University of Calgary}

Lynne Cowe Falls, PhD, P. Eng., FCAE, FCSCE, is an Associate Professor in Civil Engineering at the Schulich School of Engineering, the University of Calgary. She is a co-author of over 30 technical papers and several books in the area of pavement and infrastructure management and most recently of Current Pavement Management. With over 20 years in industry prior to joining the University of Calgary, she is a Vice-President and Board Member of the Transportation Association of Canada

\section{Robyn Paul, University of Calgary}

Robyn is a Master's student researching engineering leadership education at the University of Calgary. She graduated from Manufacturing Engineering in 2011 and worked in industry for a few years before returning to school.

\section{Mr. Gord Aker P.Eng. PCC, Logical Leadership}

Gord Aker, P.Eng. is a Professional Engineer and Executive Coach. In addition to his graduate degree in engineering, he holds the Professional Certified Coach credential from the International Coach Federation (ICF). With over 22 years of organizational leadership experience, in 2006 Aker started Logical Leadership with the objective of helping people discover, develop and deploy their innate leadership talent. His work with young professionals has included a number of Canada's top companies and he is the co-founder and primary consultant to the Maier Student Leadership Program at the Schulich School of Engineering at the University of Calgary. 


\title{
Developing a New Generation of Leadership at the University of Calgary Case Study on the Maier Student Leadership Program
}

\begin{abstract}
There is an increasing understanding amongst engineering academic institutions of the importance in educating engineers not only to have technical skills, but also professional skills. The Canadian engineering graduate attributes specifically mention certain skills, including the ability to undertake leadership roles within team environments. However, formal leadership education is rarely included in engineering curriculum. Thus, leadership training becomes the responsibility of the employer, or the skills must be acquired through on-the-job experience.
\end{abstract}

In 2006, the Schulich School of Engineering at the University of Calgary recognized and acted upon this opportunity to provide engineering students with a unique and powerful means of enhancing their leadership abilities while completing their degree programs. The Maier Student Leadership Program provides engineering students who have demonstrated an interest in leadership with the opportunity to accelerate their leadership development and realise their full leadership potential. This includes students involved in engineering students' societies, competitive teams and student clubs. This paper will describe the program structure, the content presented, and some of the feedback received from participants.

Elements of the program include individual coaching, formal learning in classroom and workshop settings, and two annual conferences. The conferences include sessions on leadership, guest panels or keynotes from industry, interactive workshops, and networking with peers. The power of the program comes from combining the practical leadership experience the students receive as a result of their roles in various student societies and project teams with leadership training, mentoring and coaching. This allows the students not only to learn new skills and knowledge but to apply and adapt these elements in a real work situation all within the security of a safe learning environment.

Reflections will be made by looking at historical feedback data and accounts from the founding members of the program, who have been involved in all of its eight years. It is anticipated that an understanding will be gained into the students' perceptions of the offered activities and the students' commitment to their own personal leadership development. This case study will provide a model for undergraduate institutions looking to provide similar engineering leadership development opportunities. 


\section{INTRODUCTION}

The University of Calgary is located in Canada's 'engineering capital' and has over 4,500 undergraduate and graduate students. Within the school there are approximately thirty clubs, teams, and associations (CTAs) active at any time and the groups are loosely organized into four categories: governance groups (Engineering Students' Society, department students' societies, etc.), competitive teams (Solar Car, FSAE Formula 1 racing, etc.), industry affiliated student chapters (IEEE, ASME, etc.), and cultural-social groups (Engineers Without Borders, Schulich Soundstage musicians, etc.). Led by students, these groups manage annual budgets that range from $\$ 5,000(\mathrm{CDN})$ to $\$ 250,000(\mathrm{CDN})$ and the total annual budget for all CTAs can be as high as \$3.2Million (CDN). Given that leading volunteers can be difficult in its own right, leadership of student groups is made even more so by youthful naivety and the fact that student leaders are working with, and trying to lead, their peers and friends without traditional employee/employer structures and accountabilities. In addition, a number of the CTAs are engaged in high profile international competitions while others represent the University of Calgary in the local and national media, activities that also demand a high degree of leadership maturity.

In 2007, building on this understanding and being well aware of the leadership challenges faced by students, the University of Calgary created the Maier Student Leadership Program (MSLP). This program provides engineering students who have demonstrated an interest in leadership with an "opportunity to accelerate their careers and realize their full leadership potential" [2]. Many current leadership programs give credit however; the MSLP is an extra-curricular program for which students do not receive academic credit for their participation. Furthermore, elements of the program are open to all students at the SSE as a means of inspiring further participation in leadership activities throughout the student's academic careers. While all students can participate in the MSLP, the primary target audience or core cohort for the program is all self-identified leaders who are actively engaged in leadership roles in the school, irrespective of year. It does this by providing the core cohort of students with the skills, knowledge and support to discover and develop their unique leadership talents. With over 350 leadership roles within the thirty-plus CTAs, approximately $10 \%$ of the student body qualifies for participation as members of the core cohort in the program. The program supports the assertion that engineers make exceptional leaders.

\section{BACKGROUND: THE PILOT PROJECT}

The Maier Student Leadership Program began with a pilot program that was funded through the generous support of the Blair Family Foundation and consisted of three initiatives.

\section{Initiative 1:}

The pilot project included two leadership conferences where the senior student leaders were gathered as a group to discuss their challenges, and needs, and to identify gaps in their leadership skills and knowledge.

The first conference was held in the spring of 2007 and was designed to facilitate the transition of student leaders from one year to the next. In addition to allowing incoming leaders the opportunity to debrief with outgoing leaders, all participants were asked to provide input into a comprehensive annual calendar of activities (the 'Calendar Calypso'). This planning process was configured to minimize conflicts between groups while maximizing opportunities for collaboration and cooperation. The exercise also provided inspiration for the incoming leaders in terms of selecting activities and events for the coming year. The Calendar Calypso process continues to be used annually and has become a major facilitation, coordination and planning tool for the entire school. The final collective calendar is posted online to facilitate access and includes over 300 events organized by students during the academic year. 
The second leadership conference was held in the fall and all students who were engaged in engineering society, project team or student club leadership activities were invited to participate. The focal point of this conference was to provide the students with both practical and theoretical knowledge on leadership. The practical information covered topics such as budgeting and forecasting, setting up bank accounts and how to maintain not-for-profit status with the University Student Union. Leadership topics covered items such as strategic planning, business planning, effective communication and team building.

\section{Initiative 2:}

In recognizing that peer collaboration can be very effective as a leadership development tool, a 'Presidents' Dinner Series' was created where the governance group presidents (presidents of the Engineering Students' Society and department students' societies) were invited to participate in monthly meetings with a Leadership Coach and the Director of Students. These events provided an opportunity for the presidents to share their respective challenges and lessons learned while at the same time providing input into the leadership program.

\section{Initiative 3:}

The third and final element of the pilot program provided one-on-one leadership coaching with a Leadership Coach for those Presidents who wanted to focus additional effort on developing their leadership talent or were experiencing particular and/or unique challenges in their roles.

At the end of the one year pilot project, feedback from the participants included requests for formal leadership training for all executive members of CTAs, more soft skills training in the areas of public speaking and developing a leadership style, tactical lessons on recruitment, retention and dealing with conflict in organizations as well a continuance of opportunities to gather all leaders together.

\section{THE MAIER STUDENT LEADERSHIP PROGRAM (MSLP)}

The success of the pilot project in the 2007-08 academic year created the momentum to seek full funding for an on-going leadership program at the Schulich School of Engineering and in the spring of 2008 this was achieved when Dr Gerald Maier agreed to provide an endowment that would fund the program in perpetuity. This funding allowed the school to increase the scope of the leadership program opening up access to all students in the SSE using a progressive implementation model as described below. The intention of opening up the program to all students was to inspire them to develop their leadership talents and take part in the leadership opportunities offered by the school.

\section{Progressive Implementation Model}

The Maier Student Leadership Program (MSLP) is delivered in a progressive manner so that those students whom demonstrate the most interest and commitment to leadership receive the greatest opportunity and support as they progress.

\section{Level One - Lunch and Learns}

The first level of program implementation is open to all SSE students and is designed to provide basic leadership awareness and fundamental skills to a broad cross section of the student body. This level was also designed to inspire an interest in leadership skills in the general student body.

At this level the MSLP provides Lunch and Learn sessions on topics such as: "Impression Management", "Public Speaking with Impact", "Networking Skills", "Business Etiquette", "Friend Friendly Feedback", "Managing Conflict", "Managing Motivation" and, the most popular sessions, "Business Cocktail Party 
Etiquette" and "Formal Dining Etiquette". The latter two sessions involved real food and cocktails in recognition that such skills are best learned through active application and immediate feedback. These etiquette sessions also reinforced the importance of understanding and respecting cultural and societal norms in a global business context. As such, these sessions were communicated as a means of preparing student leaders for the cultural and societal norms expected of a formal North American business environment with the inference that such preparation is imperative for ensuring success in any unfamiliar business environment whether local, national or global. In addition to inspiring students to embrace their leadership talent, the intention in providing these sessions is to increase the students' awareness of the importance of personal and interpersonal skills in professional environments.

\section{Level two - Leadership Conferences}

The second level of the MSLP invites all self-identified student leaders, as well as the school's prestige scholarship winners to a one-day leadership conference in the first month of the school year. 'Student leaders' includes any student who has been elected or volunteers to act in a leadership capacity on a board, major project team, student society or sanctioned club, team or association (CTAs) of the school. The total audience for the invitation list included 380 identified leadership positions (the student leaders) and 100 prestige scholars.

The fall conference includes all of the Lunch and Learn topics as described above, as well as sessions on practical and tactical topics such as; how to run effective meetings, recruitment and retention, fundraising and donor/sponsor stewardship skills, financial management and budgeting, organizing group travel, managing safety and risk, as well as logistics support. These sessions are presented in a conference format with parallel sessions being presented by faculty, staff, alumni, industry professionals and peers. As it is impossible for one student to attend all sessions, coordination is required within the student organizations to make sure that the right executive member is at the appropriate sessions for their portfolio. In addition to the sessions, each conference had a specific theme that was introduced through a plenary workshop and guest luncheon speaker. Themes included Project Management, Communication and Negotiation, Safety, Leading with Passion and Diversity.

In support of the "learn by doing" approach, at one conference, attendees were presented with a real leadership challenge wherein the groups were asked to duplicate the building of a model 'Knex' helicopter without the benefit of instructions. One fully built helicopter model was screened from view at the front of the room. One and only one designated individual from each team was permitted to examine - but not touch - the finished model and then return to their team's table and verbally convey the instructions necessary to build an exact duplicate with the available parts. No photographs were permitted. The team that finished first won a prize. Not surprisingly the winning teams typically would spend a few minutes planning and discussing their individual strengths before selecting the person who could see - and lead - the construction. Each group had to debrief the conference on their process, which provided opportunities for public speaking coaching by the conference chairs.

All registrants received twenty personalized business cards in their delegate package and were encouraged to practice networking among themselves during the coffee and luncheon breaks. For many participants, networking is the highlight of the conference as they build their network of leadership peers and at the end of day a prize is presented to the person who has exchanged the most cards. It should be clarified that the students are not actually told to collect the cards towards a prize!

Guest speakers have included senior engineers, presidents of major oil companies, senior alumni of the University of Calgary and junior alumni, all of whom share their experiences and career insights with the students. One of the most popular luncheon programs has been an alumni panel whereby recent graduates and leaders (in all cases, past presidents of the governance groups) have answered a series of questions 
based loosely on the 'the Proust Questionnaire' on the back page of Vanity Fair. Once the questionnaire is over, the microphone is turned over to the conference participants who are very eager to learn from their recent peers.

A second conference is held in the spring and, similar to the pilot conference, the emphasis for this conference is transition and coordination of annual activities through the "Calendar Calypso". At this conference, only the outgoing and incoming senior executives (president and vice-president levels) of the CTAs are invited because the junior executives (class representatives, commissioners, directors) have not yet been selected.

This half-day conference is not only a transition session but also a celebration of the previous years' activity and as with the fall conference a theme guides the program. The spring conference focuses on teaching the student leaders how to develop strategic plans, create sponsorship packages and inspire a safety oriented culture, as well as reinforcing the importance of good transition documents and succession planning. In addition, the student leaders are introduced to the leadership team of the faculty (Dean, Associate Deans, Budget Officers, etc.). In one of the early spring conferences, the plenary workshop divided the leaders into two smaller groups who had to develop a mission statement, vision, and strategic / tactical plan for a mythical engineering group. This activity allowed the students to see how many different approaches can be taken to resolve the same problem! Leaving the spring conference, each CTA is charged with the task of writing their own strategic plans and groups who submit them to the Director of Students by a set date received $\$ 200$ (CDN) towards their annual program expenses.

\section{Level three - Coaching and Mentoring of Senior Project Managers}

The third level of the MSLP is specifically aimed at those students with significant leadership responsibility as project managers of the competition teams. These leaders have the challenge of motivating a group of students to design, build and compete a car/house/toboggan at international or national venues. Frequently dealing with big companies who are their base donors/sponsors, the leaders have considerable influence, potential public profile and financial accountability. The project managers have access to a Leadership Coach to assist them in resolving on-going issues not related to academic achievement and to help them understand their personal leadership model and developmental opportunity. The MSLP provides for one-on-one coaching with a Leadership Coach as well as four off-site dinner meetings per year where the project managers/chairs can share and discuss their respective challenges. These dinner meetings have had huge benefits to the teams as they have strengthened their ties and shared resources in a manner not seen before. Each dinner has a specific theme - recruitment, retention, succession planning, training and logistical challenges - and has resulted in cost efficiencies as well as the development of a structured safety-training program at the school.

\section{Level four - Presidents' Dinners and Coaching}

The fourth and final tier in the implementation model is directed primarily at the presidents of the departments' students' societies (the governance group) Engineering Students' Society (ESS) Presidents. These individuals are integral to the University of Calgary student experience and not only represent the student body but are also accountable for the initiation and successful delivery of numerous high profile activities throughout the year. As a result of their influence and significant level of activity it is important that these individuals form a strong and interdependent working relationship. Thus, in addition to the elements of the other tiers of the MSLP, these individuals are also invited to monthly off-site dinner meetings where they can collectively explore:

- what they have learned and are learning,

$\circ$ issues and what opportunities have been observed for improvement, 
○ the challenges they may be facing within their respective departments and

$\circ$ the current status of their development as individual leaders and learners.

These monthly meetings are facilitated by a Leadership Coach and attended by the Director of Students who provides the student leaders with insight and context regarding the academic program and the operating decisions of the school. The Leadership Coach creates the opportunity to look at leadership roles and responsibilities in a different way. In addition, the Leadership Coach initiates dialog between the students to ensure they recognize the opportunity to learn from one another on an on-going basis. One of the meetings is used to provide each of the participants with a Myers Briggs Type Indicator (MBTI®) assessment with the intention of providing the students with:

- a better understanding of their personal personality preferences,

$\circ \quad$ an awareness of differences in personality types and their respective behaviours, and

- a common language to talk about and honour differences in style and type.

In addition to providing a forum for the department presidents to compare their experiences and ask one another for input, insight and advice, these meetings are also designed to recognise these students for their work in support of the MSLP and the student body.

\section{Four Year Learning Cycle}

The MSLP recognizes that many students are interested in leadership from their first year forward and so the content of the program is shifted on an annual basis to provide students with a different experience throughout the course of their degree program. Thus, a student could join the ESS Council as a first year representative and progress through to fourth year representative while enjoying a unique learning leadership educational experience each year.

Some of the program elements from a tactical perspective remain constant from year to year such as the "Calendar Calypso" (the annual calendar planning exercise) and lectures on budgeting processes for example. However the soft skills related Lunch and Learns and the other content provided during the two leadership conferences are modified each year. Conference participants are also surveyed after each conference to capture new ideas for content or to enhance areas already covered but that continue to be of interest.

\section{DISCUSSION}

Over the seven years of the MSLP, over 600 students have attended the conference, with many returning three or four times. The Lunch and Learn sessions were removed in year four of the program in favour of sessions-on-demand. Competing demands on students' time during the term (most notably, assignments and midterms) and the development of other leadership programs at the university resulted in decreasing attendance and it was decided to change from a scheduled delivery model to one where the CTAs were invited to request sessions as needed. This model was most popular with the governance groups particularly at year-end, as transition planning for new councils.

This program serves a number of different interests in a mutually supportive manner. Individual student leaders are encouraged by the school to embrace their leadership talent and develop their leadership potential. This is accomplished by opening learning opportunities for them that otherwise did not exist. Their contributions to the school are also recognized and honoured reinforcing the positive nature of their decision to step up into a student leadership role that may negatively impact their academic achievement. 
Furthermore, students participating in the program graduate with a superior and more balanced education than those focused solely on classroom and laboratory academics. Their opportunity to not just learn about leadership but to apply it in a real leadership role provides an unparalleled experience for leadership development in a safe learning environment. As a result, these individuals will have the skills and confidence to rapidly rise into leadership positions post graduation fulfilling a societal need.

Since inception of the MSLP, the student organized events, competitions and other activities are better organized and coordinated and year over year momentum of various initiatives survives intact. The MSLP actually enriches the experience of all 3200 undergraduate students at the school by assisting the leaders of these student groups in executing their roles at a higher level.

The University of Calgary also benefits from this program in that graduates from the school have had a more positive student experience as a result of these activities. In addition, the potential profile of the University is enhanced and increased within the community as a result of the school's improved performance in Engineering competitions such as the Solar Car Race, the Great Northern Concrete Toboggan Race and other such national and international events. Furthermore, the students at the SSE configure many of their events as charity fundraisers which also endears the University to the surrounding communities.

At the end of each conference, feedback was gathered via survey and participants provided not only comments on logistics (food, venue, speakers, etc.) but also gave suggestions for future conference themes. A sample of anonymous comments from the leadership conferences included:

General comments on the conference:

- "Enthusiasm, it was really high, information was on level and presented as equals. Easy to ask questions."

- "Very well organized, enthusiastic and encouraging. Very open atmosphere."

- "Good speakers with good feedback. You met halfway with us on a lot of things, so it's not all on one side [d], communication between parties was encouraged."

- "Please repeat it and do more events like this. It gave me a sense of community."

- "I really enjoyed the discussion aspects. I found that the were very informative and influential"

- "Business cards were a great idea"

- Excellent interactive environment and activities.

- I liked the vision statement exercise.

Comments on the K'nex team building exercise:

- "K'nex team based activity was very fun and it was helpful doing the project management thing right afterward."

- "It was interesting to see the different approaches to the same problem!"

- "I really enjoyed the discussion aspects. I found that they were very informative and influential"

- "I loved picking the brains of the conference speakers"

- "I liked the project management segment. It was new and different from spring and a valuable addition"

Comments on the speaker panel:

- The speaker was inspiring and well picked, i.e. very relevant topics were covered.

- Interesting topics and relevant engineering leadership topics.

- $\quad$ The speakers that were arranged to talk were very good and brought up some very important leadership issues. 


\section{CONCLUSIONS}

The Maier Student Leadership Program has captured the imagination and enthusiasm of students, faculty and industry with many from these groups expressing an interest in getting involved. This program will continue to evolve as the needs of the students and of industry are further refined however, the MSLP is clearly a unique and powerful addition to the Engineering education being received by students at the University of Calgary

The Maier Student Leadership Program is the first of its kind established at any engineering school in Canada. It provides engineering students who have demonstrated an interest in leadership with the opportunity to accelerate their leadership development and realise their full leadership potential. The power of the program comes from combining the practical leadership experience the students receive as a result of their roles in various student societies and project teams with leadership training, mentoring and coaching. This allows the students not only to learn new skills and knowledge but to apply and adapt these elements in a real work situation all within the security of a safe learning environment.

\section{REFERENCES}

[1] Crawley E.F., Malmqvist, J., Ostlund, S., Brodeur, D.R., \& Edstrom, K. (2014) Rethinking Engineering Education (2nd ed.). Springer.

[2] Beyond Engineering. (n.d.). Retrieved June 26, 2014 from the Institution website

[3] http://www.vanityfair.com/hollywood/proust-questionnaire, accessed January 15, 2015 